\title{
Linguiste-se: aplicativo de suporte para o ensino da variação linguística
}

\author{
Fernanda Forte Prichula ${ }^{1}$ \\ Kamile Anieli Wahlbrinck ${ }^{2}$ \\ César Augusto González 3
}

\section{Resumo}

Apesar de as orientações legais exigirem que a escola coloque em pauta a variação linguística, com vistas a seu reconhecimento e sua valorização, aparentemente, há poucos recursos para que o professor realize essa tarefa a contento. Ao que se sabe, livros didáticos, até recentemente, tendiam a não tratar o assunto com profundidade, e não é comum encontrar materiais de suporte ao ensino da variação linguística. 0 presente estudo objetiva preencher essa lacuna, por meio do desenvolvimento de um aplicativo que visa a auxiliar docentes e discentes a estudarem a variação e a diversidade linguística nas escolas. 0 aplicativo Linguiste-se foi desenvolvido a partir de tecnologias web como HTML, Bootstrap, JavaScript e PhoneGap. Ele apresenta três seções distintas: uma seção de conceitos, com definições para “língua", "variação linguística" e "preconceito linguístico"; um mapa linguístico, com amostras de fala de diferentes personagens brasileiros; e um jogo, com situações-problema a serem avaliadas pelos usuários. Espera-se que, com sua divulgação, 0 aplicativo possa ser usado como um recurso de suporte para o ensino de variação linguística nas escolas, de modo a contribuir com o combate ao preconceito linguístico e com a promoção de uma concepção positiva de variação linguística.

Palavras-chave: Educação linguística. Pedagogia da diversidade linguística. Preconceito linguístico.

\begin{abstract}
Even though legal guidelines require that schools put linguistic variation on their syllabus, in order to promote its recognition and appreciation, apparently, there are few resources for the teacher to carry out this task satisfactorily. Until recently, textbooks tended not to deal with the subject in depth, and it is not common to find support materials for the teaching of linguistic variation. The present study aims to fill this gap, through the development of an application that aims to help teachers and students to study linguistic variation and linguistic diversity in schools. The Linguiste-se application was developed using web technologies such as HTML, Bootstrap and JavaScript. It has three distinct sections: a concepts section, with definitions for "language”, "linguistic variation” and "linguistic prejudice”; a linguistic map, with speech samples from different Brazilian characters; and a game, with problem situations to be evaluated by users. It is hoped that, with its dissemination, the application can be used as a support resource for the teaching of linguistic variation in schools, in order to contribute to the fight against linguistic prejudice and the promotion of a positive conception of linguistic variation.
\end{abstract}

Key words: Linguistic education. Pedagogy of linguistic diversity. Linguistic prejudice.

\footnotetext{
${ }^{1}$ Técnica em Informática. Instituto Federal Farroupilha - Campus Frederico Westphalen. E-mail: Instituto Federal Farroupilha - Campus Frederico Westphalen. E-mail: fernandaprichula@hotmail.com

2 Especialista em projetos e desenvolvimento de aplicativos móveis. Instituto Federal Farroupilha - Campus Frederico Westphalen.E-mail: kamile.wahlbrinck@iffarroupilha.edu.br

3 Doutor em Linguística Aplicada. Instituto Federal Farroupilha - Campus Frederico Westphalen. E-mail: Instituto Federal Farroupilha - Campus Frederico Westphalen. E-mail: cesar.gonzalez@iffarroupilha.edu.br
} 
1 Introdução

Os Parâmetros Curriculares Nacionais (BRASIL, 1998), assim como a Base Nacional Curricular Comum (BRASIL, 2019), preveem que a disciplina de Língua Portuguesa trabalhe com variação e diversidade linguística no Brasil. Entretanto, os professores de Língua Portuguesa aparentemente encontram dificuldades em localizar materiais para trabalhar esses temas com seus alunos.

A título de exemplo, entre muitos estudos disponíveis hoje em dia, destacamos, sobre o tratamento da variação linguística em livros didáticos para ensino médio, González (2015), que analisou as coleções de livros didáticos aprovadas pelo Programa Nacional do Livro para o Ensino Médio de 2009 e constatou que, apesar de todos os livros didáticos abordarem a variação linguística - o que é esperado, em razão das demandas legais -, os livros mais adotados nas escolas, em geral, o fazem de maneira bastante superficial. Muitas vezes, 0 fazem por meio de piadas e outros textos que apresentam a variação de forma estereotipada. Além disso, os livros mais adotados naquela edição do PNLD valorizavam a variação lexical e a dimensão geográfica da variação linguística. Dessa forma, todo livro didático destacava a variedade de palavras para pipa (papagaio, pandorga) ou para menino (guri, moleque, piá, rapazote...) e como essas palavras são preferidas aqui ou ali no território brasileiro. No entanto, pouca atenção se dava à variação em nível fonético-fonológico ou morfossintático e quase não se abordam as questões relativas à dimensão social da variação linguística - e, portanto, suas consequências em termos de preconceito linguístico.

Dessa forma, tais livros faziam com que o discurso mais propagado aos estudantes não enfocasse variação e a diversidade linguísticas. Nesse sentido, esse distanciamento entre os estudantes e a noção de que a língua é variável e plural contribui para que a população cresça desinformada por não conhecer a enorme variação e diversidade linguísticas existente no Brasil. Essa falta de informação pode contribuir para que se acabe por discriminar maneiras diferentes de falar.

Essa depreciação da maneira do outro falar é chamada de preconceito linguístico.

O preconceito linguístico se baseia na crença de que só existe [...] uma única língua portuguesa e que ela seria ensinada nas escolas, explicada nas gramáticas e catalogadas nos dicionários. Qualquer manifestação linguística que escape desse triângulo escola-gramática-dicionário, é considerada, sob a ótica do preconceito 


\section{॥ LÍNGUATEC}

linguístico, "errada, feia, estropiada, rudimentar, deficiente" e não é raro a gente ouvir que "isso não é português". (BAGNO, 2007, p. 40).

Normalmente, esse prejulgamento dirige-se às variedades linguísticas mais informais e ligadas às classes sociais menos favorecidas, as quais, via de regra, têm acesso deficitário à educação e aos bens da cultura escrita. Com efeito, o teor de desprezo causa impactos que podem resultar no silenciamento dos sujeitos, que deixam de falar, de se posicionar socialmente, em razão de certo temor de que sua expressão linguística seja alvo de preconceito. Desse modo, precisamos assumir que os comportamentos linguísticos devem ser respeitados.

Na sociedade de falantes do Português do Brasil, não há uma língua homogênea, pois existem múltiplas variedades linguísticas em toda a extensão do país, que são resultado do impacto de diversos fatores estruturais, culturais e sociais, os quais implicam em uma língua bastante diversa. Portanto, concordamos com Faraco (2012), que afirma que não há uma única forma correta de se empregar a língua.

Nas escolas, o preconceito linguístico acontece frequentemente e é um problema que muitas vezes passa despercebido, pois é muito pouco comentado socialmente. Uma criança ou um jovem que porventura passe por episódios nos quais é diminuído/a ou ridicularizado/a pelos seus colegas em decorrência da sua forma de falar, pode passar a evitar se manifestar com o medo do julgamento, privando-se do direito de se expressar.

A nosso ver, para combater esse preconceito com a variação linguística, é necessário abordar o tema e explicar o porquê dela existir, objetivando conscientizar os estudantes desde cedo sobre essas diferenças, proporcionando um olhar de cuidado e de empatia com o outro além de um olhar de valorização da diversidade. Segundo os Parâmetros Curriculares Nacionais (1998, p. 82), “a escola precisa cuidar para que não se reproduza em seu espaço a discriminação linguística. [...] É importante que o aluno [...] entenda que todas as variedades linguísticas são legítimas e próprias da história e da cultura humana".

Com base nisso, esta pesquisa visa a construir um aplicativo híbrido, ou seja, que funcione como sistema web e aplicativo, com o intuito de contribuir com materiais de estudo sobre a variação linguística para que professores de Língua Portuguesa e alunos do ensino básico a estudem, informando as pessoas acerca da pluralidade e da diversidade linguísticas presentes no Brasil. 0 presente estudo se propõe, também, a divulgar o aplicativo para 
professores de Língua Portuguesa que se interessem pelo tema e pelo uso de novas tecnologias em sala de aula, além contribuir com pesquisas nas áreas de Informática e de Língua Portuguesa. $O$ aplicativo conta com conceitos importantes que embasam o estudo da variação linguística, exemplos de variedades linguísticas divididos entre as cinco regiões brasileiras, além de um jogo de histórias para testar os conceitos estudados.

Para a apresentação deste artigo, as próximas seções são organizadas da seguinte forma: a seção 2 descreve conceitos importantes para a compreensão do presente estudo, como também apresenta algumas pesquisas relacionadas; a seguinte, de número 3, expõe como o trabalho foi desenvolvido; a seção 4 apresenta os resultados obtidos; e; por fim, a seção 5 aborda as considerações finais e os trabalhos futuros.

2 Referencial teórico

As subseções a seguir conceituam os principais conceitos utilizados ao longo deste estudo, com o intuito de esclarecê-los, além de apresentar projetos similares.

2.1 Variação linguística

Segundo Faraco (2012), uma língua é composta por um conjunto de variedades, e, portanto, não é homogênea. Essa diversidade é oriunda do entrecruzamento de uma série de variáveis linguísticas e sociais, entre elas o gênero do falante, sua região geográfica de origem, sua história de escolarização, etc. Podemos observar a variação linguística na sonoridade da língua (me[z]mo me[h]mo me[ ]mo, etc.), na escolha de palavras e expressões utilizadas pelos diferentes grupos de falantes (guri menino $\sim$ moleque $\sim$ piá etc.) e na realização ou não de certas marcas morfossintáticas (como a concordância verbal, em nós vamos nós vamo nóis vamo nóis vai a gente vai etc.).

Bagno (2017, p. 474) explica a preferência pelo termo variedade, em detrimento de dialeto, socioleto ou outros possíveis:

o termo variedade linguística pretende ser uma forma neutra [...] para se referir a qualquer tipo especifico de linguagem. [...] As variedades podem ser regionais (mineira, carioca, baiana etc.) ou sociais (quando definidas por critérios como idade, 


\title{
II LÍNGUATEC
}

sexo, classe social, grau de escolarização etc.), e também estilísticas (segundo o grau de maior ou menor formalidade da fala ou da escrita).

\subsection{Preconceito linguístico}

Por diferentes motivos, as pessoas são capturadas pela ideologia da língua padrão (MILROY, 2012), e por ignorância, por má-fé ou por desejo de distinguir-se de outros, não reconhecem a variação linguística. Faraco (2012) afirma que a língua, então, se torna um motivo de discriminação social, e suas variedades passam a ser tratadas como formas incorretas de falar. É interessante notar que esse julgamento é, majoritariamente, professado por grupos sociais que possuem privilégios econômicos e, por isso também, com acesso à escolaridade e à língua escrita. Além disso, em geral, o julgamento atinge as camadas sociais que dispõem de pouco recurso econômico e pouco letramento bem como os representantes de minorias étnicas e os que vivem em ambientes rurais ou rurbanos ${ }^{4}$. Nesse sentido, podese dizer que essa cultura do preconceito com a língua, que afeta escolas e ambientes de trabalho, está enraizada na nossa sociedade devido a um problema maior: a desigualdade social.

O preconceito linguístico parece passar despercebido socialmente e, consequentemente, acaba sendo um tanto desconhecido. A escola é o ambiente adequado para que se dialogue sobre o assunto, como destacam os PCN:

\begin{abstract}
para cumprir bem a função de ensinar a escrita e a língua padrão, a escola precisa livrar-se de vários mitos: o de que existe uma forma correta de falar, o de que a fala de uma região é melhor da que a de outras, o de que a fala correta é a que se aproxima da língua escrita, o de que o brasileiro fala mal o português, o de que 0 português é uma língua difícil, o de que é preciso consertar a fala do aluno para evitar que ele escreva errado. Essas crenças insustentáveis produziram uma prática de mutilação cultural. (BRASIL, 1998, p. 31).
\end{abstract}

Essa premissa também se identifica na BNCC, segundo a qual se espera do aluno as habilidades de

Conhecer algumas das variedades linguísticas do português do Brasil e suas diferenças fonológicas, prosódicas, lexicais e sintáticas, avaliando seus efeitos

\footnotetext{
${ }^{4}$ Espaço com características urbanas e rurais em que há habitat e atividades rurais, bem como edificações próprias de áreas urbanas.
} 


\section{॥ LÍNGUATEC}

semânticos. Discutir, no fenômeno da variação linguística, variedades prestigiadas e estigmatizadas e o preconceito linguístico que as cerca, questionando suas bases de maneira crítica. (BRASIL, 2019, p. 83).

Para que os professores e alunos que almejam questionar o preconceito linguístico tenham acesso a fontes de informação para observar, comparar e analisar diferentes variedades linguísticas, a tecnologia pode ser bastante útil. Ela pode se apresentar como um interessante instrumento, tendo em vista que ela oferece recursos audiovisuais, acesso a notícias e a softwares educativos.

Com efeito, entendemos que, na educação, a tecnologia atua como uma ferramenta que visa a contribuir para que as pessoas conheçam e valorizem a variação e a diversidade linguístico, visto que ela permite um leque maior de oportunidades de aprendizagem e interatividade para discentes e docentes (MACHADO; LIMA, 2017, p. 45). Consoante a isso, os dispositivos tecnológicos estão presentes na vida cotidiana de muitos alunos e professores, permitindo a aprendizagem dentro e fora da sala de aula.

Além do mais, acredita-se que é possível enfrentar o preconceito linguístico por meio do conhecimento da variedade e da diversidade linguísticas de modo que o estudante passe a compreender que a língua não é homogênea. Para isso, os Parâmetros Curriculares Nacionais (1998, p. 82) sugerem a “análise [...] da linguagem popular na comunicação cotidiana, na mídia e nas artes, analisando depoimentos, filmes, peças de teatro, novelas televisivas, música popular, romances e poemas". Nesse sentido, o aplicativo Linguiste-se contribui com a apresentação de uma seleção de vídeos interessantes e com a proposição de certas análises linguísticas.

\subsection{Projetos similares}

O aplicativo "Chega de Preconceito"5, disponível na Play Store, informa conceitos para definir seis tipos de preconceito, sendo eles: homofobia, intolerância religiosa, machismo, padrões estéticos, racismo e xenofobia. “Chega de Preconceito” utiliza de amostras de vídeos, músicas, notícias, reportagens e livros que explicam esses preconceitos. Além disso, o

\footnotetext{
${ }_{5}^{5}$ Disponível em: <https://play.google.com/store/apps/details?id=br.edu.ifrn>; último acesso em 06/07/2019.
} 
aplicativo conta com um jogo de apresentação de situações de preconceito para testar se as opiniões do usuário possuem caráter respeitoso ou preconceituoso.

Antunes (2015) desenvolveu o website "Pelo Fim do Preconceito Linguístico6", que possui materiais sobre o tema em pauta. Esse portal informa o usuário, por meio de conceitos relacionados ao preconceito linguístico, vídeos explicativos e textos informativos. Ademais, esse portal conta com um plugin ${ }^{7}$ do aplicativo Facebook, uma busca de palavras-chave e, ainda, é possível enviar materiais para o site sobre o assunto preconceito linguístico.

Além desses projetos, não se tem conhecimento de outros aplicativos ou estudos semelhantes. No entanto, diferentemente do aplicativo "Chega de preconceito" e do website “Pelo Fim do Preconceito Linguístico”, o aplicativo Linguiste-se aborda com exclusividade 0 preconceito linguístico, dispondo de definições importantes para a sua compreensão. 0 aplicativo, que também possui versão para a web, conta com um mapa do Brasil interativo, que apresenta demonstrações de fala de cada região do país através de vídeos do YouTube e, ainda, promove reflexões sobre as formas de falar dos personagens dos vídeos. Finalmente, 0 Linguiste-se conta com um jogo de histórias para testar os conhecimentos aprendidos.

\section{Metodologia}

Esta seção tem como objetivo apresentar os passos do desenvolvimento do Linguistese.

O procedimento metodológico inicial desde estudo consistiu em definir de que forma seria adequado abordar a temática proposta no aplicativo, tendo em vista que o Linguiste-se se destina à educação e exige uma didática adequada e de fácil compreensão para os seus usuários. Assim, definiu-se que seriam apresentados conceitos, os quais serviriam como base para a compreensão do que é variação linguística e preconceito linguístico, pois como explica Breitbach (1998, p. 123), “o conceito serve como ponto de partida da observação, uma vez que designa, por abstração, aquilo que num primeiro momento não é diretamente perceptível". Dessa forma, esperava-se fazer com que os usuários tivessem um embasamento

\footnotetext{
${ }^{6}$ Disponível em: <http://www.pelofimdopreconceitolinguistico.com/>; último acesso em 06/03/2020.

7 Módulo de extensão de um software que é usado para adicionar funções a outros programas. No caso, a ferramenta de comentários do Facebook foi adicionada no portal "Pelo Fim do Preconceito Linguistico".
} 
teórico que possibilite um melhor entendimento e proveito do que viria a seguir: as demonstrações de fala.

Haja vista que o fenômeno da variação linguística é mais claramente percebido ao ouvirem-se formas diferente de falar, é importante que se ouçam diferentes demonstrações de fala para que ela seja compreendida. Dessa forma, definiu-se que haveria um mapa brasileiro fracionado nas cinco regiões político-administrativas (Norte, Nordeste, Sul, Sudeste e Centro-Oeste). Para cada região, foi desenvolvida uma página na qual há a apresentação trechos de vídeos com personagens brasileiros, que tivessem nascido e vivido na região em questão. Os vídeos foram selecionados da plataforma YouTube e os personagens foram definidos em razão de sua origem geográfica, sua posição na hierarquia socioeconômica, seu grau de escolarização e seu gênero. O objetivo de considerarmos todas essas variáveis era proporcionar uma maior diversidade de falantes $e$, portanto, de variedades linguísticas ${ }^{8}$. Somado a isso, em cada página, há um questionamento para que o leitor pense a respeito do vídeo a que assistiu e, a seguir, há uma resposta para pergunta feita, destacando aspectos relevantes das variedades linguísticas mobilizadas pelos personagens do vídeo. Vale ressaltar que, apesar do design ser proposto no formato de um mapa, há múltiplas variedades linguísticas sendo analisadas no aplicativo e não se trata exclusivamente de variedades geográficas.

Além disso, determinou-se que haveria um jogo com o objetivo de testar os conhecimentos dos usuários. Ele seria composto de histórias demonstrando casos de preconceito com a língua e apresentaria respostas de caráter positivo e negativo. A cada resposta de caráter positivo (isto é, sem preconceito linguístico), a questão é considerada como certa e soma um acerto, no caso de resposta de caráter negativo (isto é, com preconceito linguístico), o jogador não soma acertos e recebe uma explicação de por que errou a resposta.

De modo a proporcionar que o usuário possa enviar um feedback quanto ao sistema, engendrou-se uma página de contato para a versão web do Linguiste-se, na qual seria possível enviar uma mensagem para o e-mail do sistema. Logo após essas definições, realizou-se um esboço das páginas do sistema.

\footnotetext{
${ }^{8}$ Apesar disso, não se pode afirmar que houve um controle sistemático dessas características, a fim de constituir células como em um estudo sociolinguístico quantitativo clássico.
} 
Posteriormente, foi realizado o levantamento de requisitos para que ficasse claro e detalhado o que teria no aplicativo. Para tanto, os requisitos foram divididos em 'requisitos funcionais', que indicam as funcionalidades e necessidades esperadas, e 'requisitos nãofuncionais', que expressam características como de desempenho e usabilidade, como também as restrições do aplicativo. Foram selecionados os seguintes requisitos funcionais:

- O aplicativo deve mostrar um mapa do Brasil que será fracionado em cinco regiões, cada fração sendo um botão que, quando clicado, direciona-se para a página da região brasileira selecionada.

- Ao clicar sobre uma região, o aplicativo deve mostrar dois vídeos de personagens brasileiros que nela residem, com a apresentação de uma biografia dos personagens, uma pergunta para que o usuário reflita sobre usos linguísticos e uma resposta a essa pergunta.

- Na seção do jogo, o aplicativo deve mostrar três alternativas para responder a cada pergunta.

- $\quad$ aplicativo deve contabilizar os acertos das questões do jogo.

- O aplicativo deve emitir uma pontuação ao final do jogo.

- A versão web do aplicativo deve permitir o envio de e-mail para os administradores do site.

A seguir, foram selecionados os requisitos não funcionais:

- A interface disponível para o usuário deve ser simples e intuitiva.

- Deve haver histórias disponíveis na seção jogo.

- O aplicativo deve ser desenvolvido na linguagem de programação JavaScript.

- Os vídeos, da plataforma YouTube, funcionarão apenas com acesso à internet.

- A usabilidade do sistema deve ser de fácil aprendizagem.

- A aplicação deverá ser desenvolvida com ferramentas gratuitas. 


\section{$\Perp$ LÍNGUATEC}

Como terceiro passo, deu-se a construção das páginas, utilizando-se o editor de texto Sublime Text para implementar o código fonte. A base das páginas foi desenvolvida com a linguagem de marcação HTML e a estilização com o framework Bootstrap. Para as funcionalidades como o jogo e botões com mensagens escondidas, foi utilizada a linguagem de programação JavaScript. Já para a página de contato, foram utilizadas as linguagens de programação PHP (Hypertext Preprocessor), que é uma linguagem utilizada para desenvolvimento web que funciona do lado do servidor, e a linguagem JavaScript. Além disso, foi aplicado o Ajax (Asynchronous JavaScript and $X M L$ ), que é um recurso do JavaScript descrito por Silva (2009, p. 23) como “uma técnica de carregamento de conteúdos em uma página web com uso do JavaScript e [...] qualquer linguagem de marcação ou programação capaz de ser recuperada em um servidor", neste caso, o PHP.

Em seguida, com o auxílio de um professor especialista em linguística, desenvolveuse o conteúdo linguístico do sistema: os conceitos de língua, variação linguística e preconceito linguístico. Escolharam-se, também, vídeos do YouTube que pudessem ser utilizados como demonstrações de fala. Para esse fim, fez-se um estudo dos conceitos por meio da leitura de Bagno (2007; 2017) e Faraco (2012). Esses livros abordam, língua, variação linguística e preconceito linguístico. Foi a sua leitura que permitiu o desenvolvimento da seção de conceitos no Linguiste-se. Além disso, pesquisaram-se em sites da web as biografias das personagens dos vídeos selecionados, de modo que se pudesse refletir sobre suas variedades linguísticas.

Para efetivar a construção do aplicativo Linguiste-se, utilizou-se a ferramenta PhoneGap. Tal ferramenta permite transformar os códigos programados para web em um aplicativo. Com o serviço online PhoneGap Build, deu-se a compilação do código em um aplicativo.

Por fim, a fim de realizar uma avaliação preliminar e informal do aplicativo, o Linguistese foi apresentado a professores de Pedagogia e de Língua Portuguesa de ensino básico, médio e superior, totalizando nove professores, os quais fizeram uso do aplicativo por uma semana e, em seguida, analisaram o conteúdo linguístico e a sua usabilidade. Esses profissionais são conhecedores do conteúdo produzido e, como educadores, puderam avaliar preliminar e informalmente o aplicativo como recurso de ensino. Sua contribuição com o presente estudo se resume a uma avaliação superficial do aplicativo. Tal avaliação, evidentemente, é de 
natureza exploratória e não deve ser considerada como resultado de pesquisa, embora o retorno obtido desses educadores sugira que o aplicativo atinge seus objetivos. A avaliação foi realizada por meio de formulário do Google e suas perguntas constam no apêndice A.

4 Resultados e discussão

Nesta seção, apresentamos, primeiramente, o aplicativo Linguiste-se, seus recursos e exemplificamos alguns de seus conteúdos. Em seguida, comentamos a avaliação preliminar e informal do aplicativo realizada por professores de Pedagogia e de Língua Portuguesa.

4.1 $O$ aplicativo Linguiste-se

Em primeiro lugar, serão apresentadas as telas da página inicial e da seção de conceitos do aplicativo Linguiste-se. Na estrutura do aplicativo, a primeira página com a qual o usuário terá contato é a página inicial exibida na Figura 1. Nela, há um botão no canto superior direito o qual, ao ser clicado, abre as opções que direcionam para as páginas do mapa linguístico, dos conceitos e do jogo. De modo similar, a imagem do mapa que está no centro da página possui botões em cada balão de diálogo com o mesmo fim: direcionar para a página indicada pelo texto escrito. Ademais, há três jumpbotrons, que são componentes em forma de caixa que organizam o texto, no plano inferior, os quais dão as boas vindas e explicam o objetivo do aplicativo. 


\section{$\|$ LÍNGUATEC}

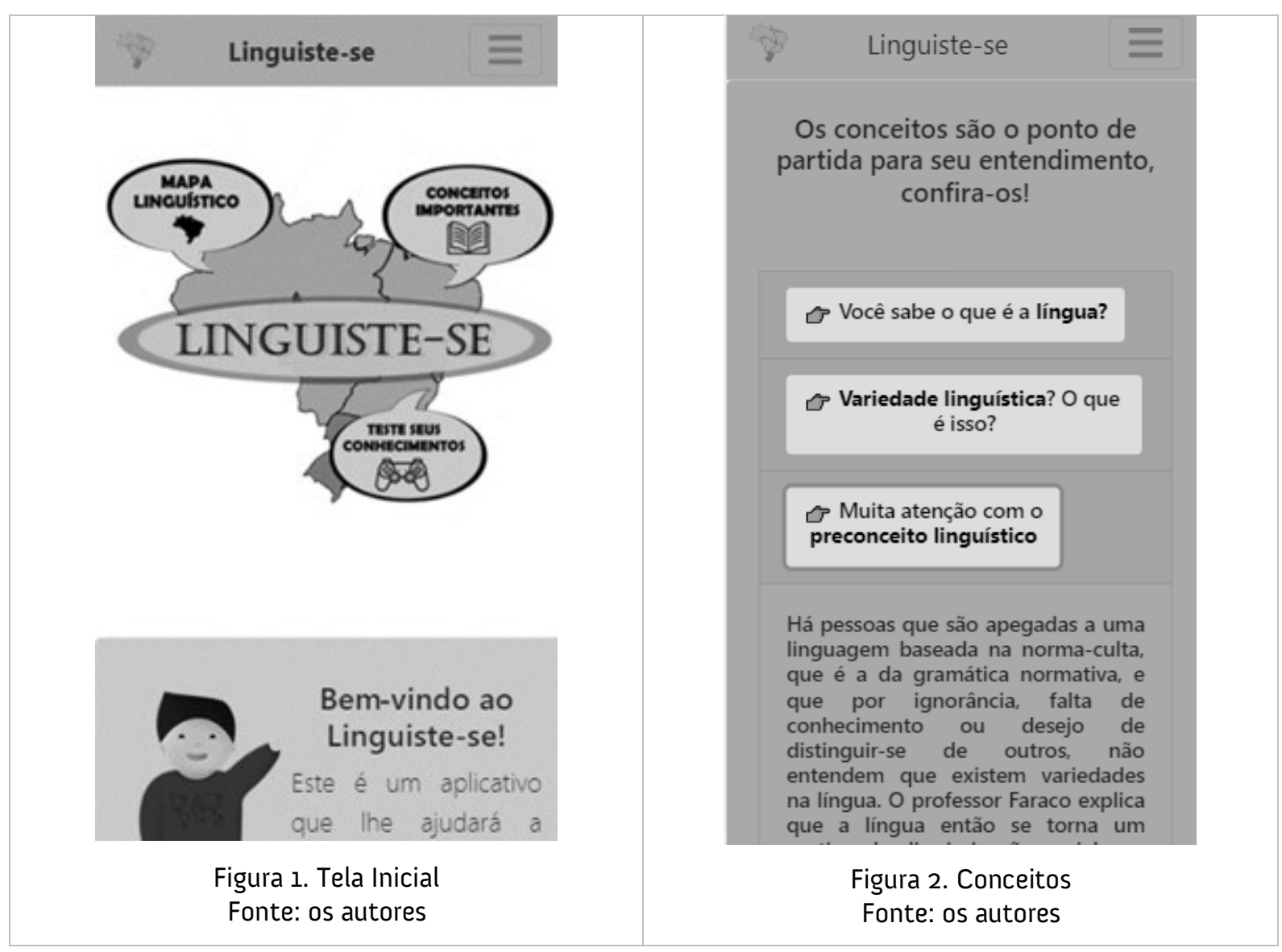

Ao selecionar a opção conceitos, a página da Figura 2 é aberta. Esta dispõe de três collapses, que são botões recolhíveis, os quais mostram o conceito oculto quando clicados. A página tem o objetivo de apresentar uma base teórica para os principais tópicos linguísticos mencionados ao longo do trabalho, a fim de sanar dúvidas referentes à língua, à variedade linguística e ao preconceito linguístico.

Na seção mapa linguístico, há a imagem central do mapa do Brasil exemplificada na Figura 3, abaixo. A imagem é dividida nas cinco regiões do Brasil e cada uma delas constituise um botão que leva até a página da região. Em cada região, há vídeos de dois personagens brasileiros que representam as variedades tipicamente mobilizadas naquela região do país. Associados ao vídeo, há uma biografia da pessoa que o protagoniza e uma pergunta para o usuário pensar sobre o modo de falar que escutou. Após a pergunta, há um botão com a resposta oculta, que, ao ser clicado, exibe a resposta. A Figura 4 mostra um exemplo de personagem brasileiro associado à Região Sul. 


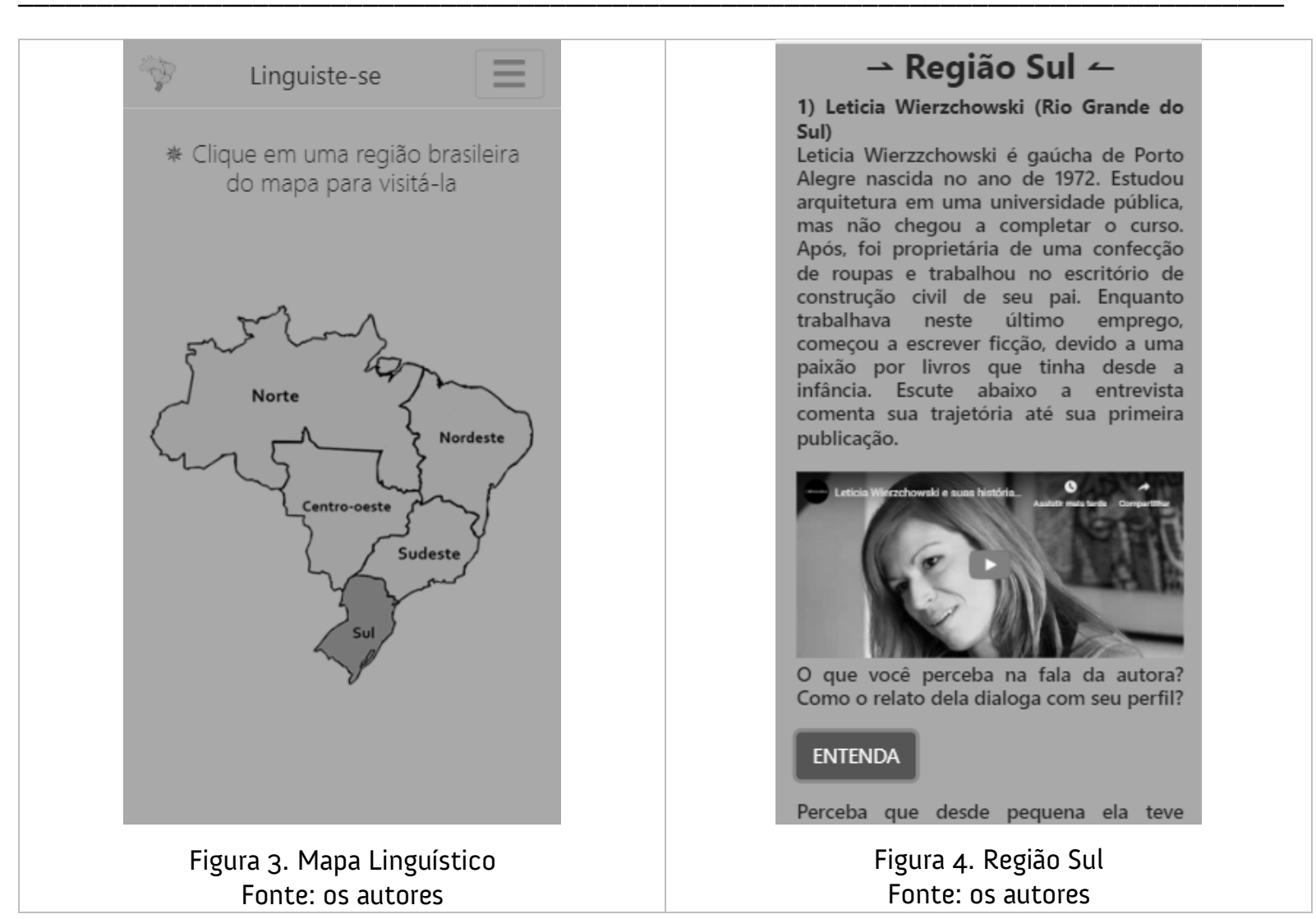

No quadro 1, abaixo, há um exemplo de conteúdo linguístico desenvolvido. Neste caso, apresenta-se e reflete-se sobre o Samba do Arnesto, de Adoniran Barbosa, que viveu em São Paulo, estado pertencente à região Sudeste do Brasil. 
1) Samba do Arnesto, Adoniran Barbosa (São Paulo)

Conheça Adoniran Barbosa, nome artístico de João Rubinato. Ele nasceu na cidade de Valinhos, interior de São Paulo, em 6 de agosto de 1910. Filho de imigrantes italianos, abandonou os estudos ainda no primário para trabalhar, pois necessitava ajudar a família numerosa. Foi um compositor, cantor, humorista e ator brasileiro. Misturou o sotaque do interior aos trejeitos italianos, criou um linguajar novo a partir de suas letras. Ele encarou a cidade grande com os olhos de um caipira. Adoniran Barbosa ficou conhecido nacionalmente como o inventor e pai do samba paulista.

Escute abaixo a música Samba do Arnesto.

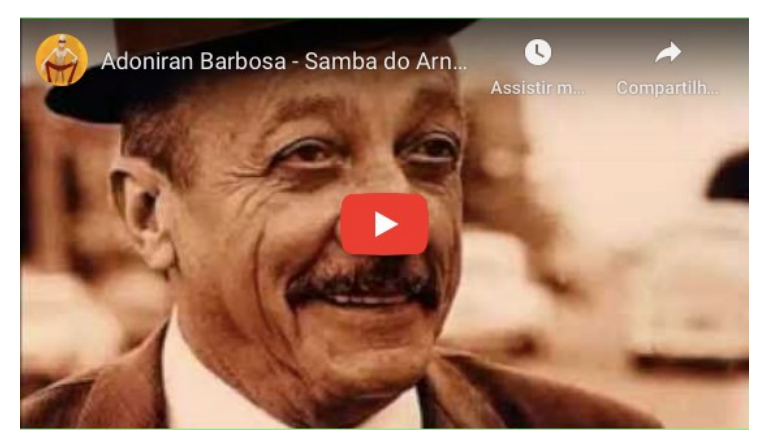

O que você observa na letra e na linguagem empregada na música? Como ele fala: "nós fomos", "vamos" e "voltamos"?

\section{ENTENDA!}

Há, na letra da música, um relato em que o cantor fora convidado juntamente com seus amigos para ir em um samba, mas, ao chegar lá, não havia ninguém. Note que ele fala "nóis fumo", "vai" e "vortemo" para dizer "fomos", "vamos" e "voltamos", respectivamente. Que outras formas ainda você já escutou essas palavras? Que formas você e seus amigos tipicamente falam?

Perceba como a linguagem empregada é popular. 0 artista utiliza o linguajar popular das pessoas das classes mais baixas e dos menos favorecidos, sem se preocupar com as críticas que isso possa gerar. Inclusive, às críticas que recebia sobre suas canções, ele simplesmente rebatia: "só faço samba pra povo. Por isso faço letras com erros de português, porquê é assim que o povo fala. Além disso, acho que o samba, assim, fica mais bonito de se cantar."

Perceba também a importância da canção: ela possibilita que o povo paulistano se sinta representado nas canções. Ademais, o seu samba é contagiante e isso que importa: que as pessoas se divirtam e se vejam representadas na cultura, na política, no esporte!

Quadro 1. Conteúdo sobre Adoniran Barbosa, na região Sudeste do Brasil. Fonte: Os autores. 


\section{॥ LÍNGUATEC}

Outros personagens brasileiros que constam no aplicativo são:

\begin{tabular}{|c|l|}
\hline \multirow{2}{*}{ Região Centro-Oeste } & Alzira Espíndola, musicista mato-grossense \\
\cline { 2 - 2 } & Moradores de Poconé, populares mato-grossenses \\
\hline \multirow{2}{*}{ Região Nordeste } & Ariano Suassuna, escritor paraibano \\
\cline { 2 - 2 } & Patativa do Assaré, poeta popular cearense \\
\hline \multirow{2}{*}{ Região Norte } & Dona Onete, cantora popular paraense \\
\cline { 2 - 2 } & Paes Loureiro, intelectual paraense \\
\hline \multirow{2}{*}{ Região Sudeste } & Adoniran Barbosa, musicista paulista \\
\cline { 2 - 2 } & Chico Buarque, musicista carioca \\
\hline \multirow{2}{*}{ Região Sul } & Baitaca, musicista gaúcho \\
\cline { 2 - 2 } & Letícia Wierzchowski, escritora gaúcha \\
\hline
\end{tabular}

Quadro 2. Personagens brasileiros no aplicativo.

Fonte: Os autores.

A Figura 5 apresenta a página inicial do jogo. Após clicar em começar, abre-se a página da Figura 6, em que são apresentados quatro relatos de personagens e há três alternativas em cada um, sendo uma a resposta correta para a questão feita. Quando uma alternativa for selecionada, é possível responder e avançar para a próxima questão. Ao final das quatro perguntas, há o gabarito das questões. 


\section{$\Perp$ LÍNGUATEC}

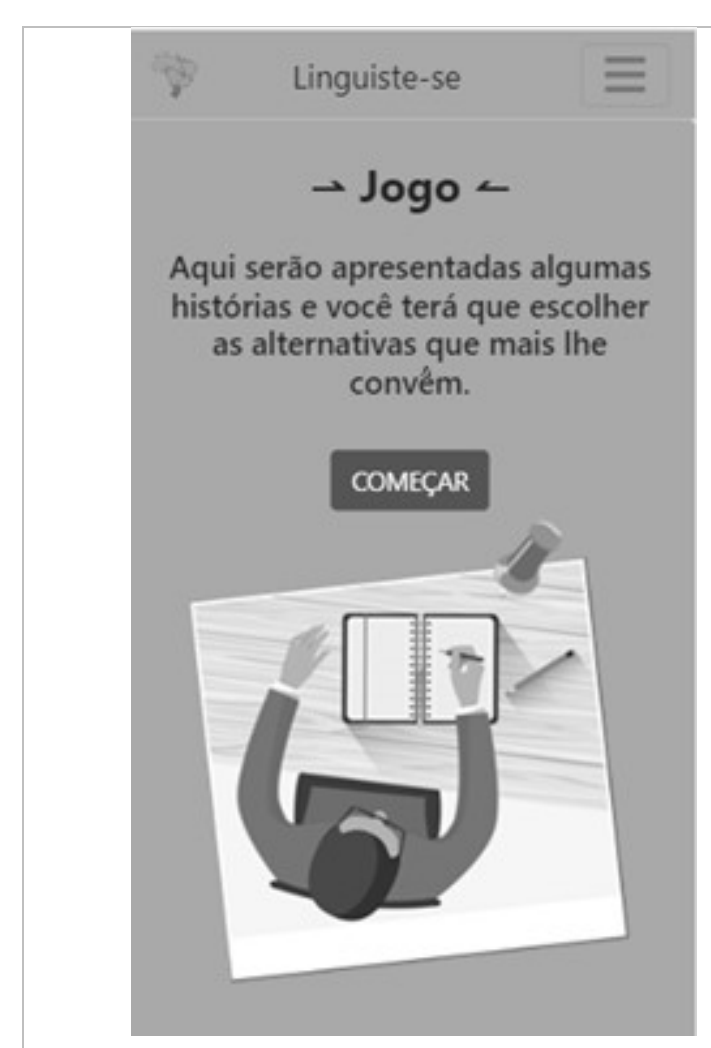

Figura 5. Página inicial do jogo. Fonte: Os autores.
Me chamo Ana e hoje no intervalo da minha aula estava conversando com meus colegas quando um deles começou a rir de mim, dizendo que é uma vergonha falar "nóis vamo na palestra". Não soube o que fazer na hora e sai de perto. Isso me deixou triste e envergonhada. Você poderia me ajudar a entender isso?

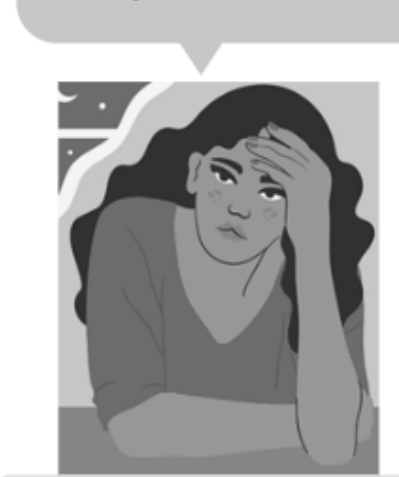

Acho que eles estudam muito a norma culta e identificaram que você falou errado. Eu concordo com eles.

Eles provavelmente falam diferente

Figura 6. Jogo. Fonte: Os autores.

Ademais, o aplicativo também dispõe de uma versão web igual à apresentada acima, para ampliar a facilidade de acesso ao conteúdo produzido. Essa versão pode ser acessada pelo seguinte hiperlink < http://inf.fw.iffarroupilha.edu.br/ fernanda.forte/Linguistese/index.html > (último acesso em 02/05/2020).

\subsection{Avaliação preliminar do aplicativo}

O aplicativo foi submetido a uma avaliação preliminar e informal de nove professores de Pedagogia e de Língua Portuguesa em atuação na educação fundamental, média e superior. Depois de utilizarem-no por uma semana, submetemos aos professores um formulário do Google com algumas perguntas fechadas sobre a avaliação do aplicativo e uma pergunta aberta com pedido de sugestões de melhorias ${ }^{9}$.

\footnotetext{
9 questionário completo está disponível no apêndice $\mathrm{A}$.
} 
Ainda que o número de pessoas que se propuseram a avaliar o aplicativo seja bastante pequeno e que as avaliações devam ser analisadas com um olhar crítico, em razão das evidentes limitações da técnica empregada, optamos por apresentar esses dados porque eles indiciam que os professores entrevistados consideram, de um modo geral, o aplicativo "bom" ou "muito bom", como o gráfico abaixo sugere (Figura 7).

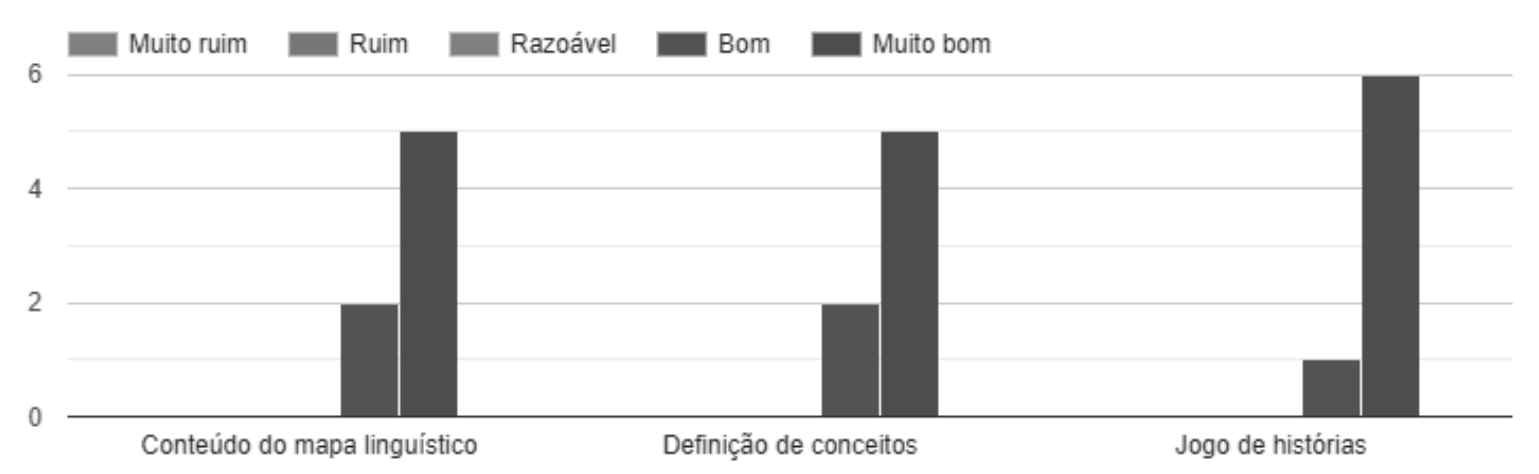

Figura 7. Avaliação preliminar e informal de alguns aspectos do aplicativo.

Fonte: Os autores.

Com relação ao pedido de sugestões e de melhorias para o aplicativo, houve apenas colocações de que (i) o aplicativo é interessante, (ii) o aplicativo poderá auxiliar no fazer pedagógico em função da escassez de materiais deste conteúdo e (iii) o aplicativo é bom e criativo. Os participantes desse processo preliminar e informal de avaliação do aplicativo, portanto, consideraram-no bom e útil. Com efeito, não nos é possível afirmar que o aplicativo atinge seus objetivos sem uma metodologia de avaliação cuidadosamente estruturada para tanto. Contudo, as avaliações recebidas indiciam que o aplicativo produzido neste estudo pode contribuir com a discussão a respeito de variação linguística na escola.

5 Considerações finais

O aplicativo Linguiste-se foi desenvolvido para dar suporte ao ensino da variação linguística, através da apresentação de informações de forma dinâmica e didática. Seu propósito consiste no combate ao preconceito linguístico por meio da divulgação de informações a respeito da variação linguística e da reflexão a respeito da fala de diferentes personagens brasileiros representados em vídeos disponíveis no YouTube. 


\section{॥ LÍNGUATEC}

O preconceito linguístico é um problema que se atravessa na vida de muitas pessoas, inclusive no ambiente escolar, fazendo com que se sintam ridicularizadas e diminuídas. Para combater o preconceito linguístico, está previsto nos Parâmetros Curriculares Nacionais (1998) que a escola desconstrua mitos como o de que a norma-padrão é a única variedade linguística possível e correta. Entretanto, ao que tudo indica, os professores dispõem de poucos materiais para trabalhar a variação linguística, já que os livros didáticos abordam essa questão de maneira superficial e estereotipada (GONZÁLEZ, 2015).

Partindo dessa problemática, este estudo propôs o desenvolvimento do aplicativo Linguiste-se com o objetivo de disponibilizar material de estudo sobre língua, variação linguística e preconceito linguístico no Brasil de forma dinâmica e didática. 0 estudo mostra que o Linguiste-se atinge esse objetivo, sendo capaz de contribuir para o ensino e a aprendizagem de questões relacionadas à língua, à variação linguística e ao preconceito linguístico. Professores poderão incluir o aplicativo em seus planos de ensino e torná-los mais flexíveis, empregando novas tecnologias em sala de aula.

Dentre as limitações no desenvolvimento do estudo, como já apontamos, nossa técnica de avaliação do aplicativo é muito limitada. De fato, não foi possível testar o aplicativo com estudantes e professores dentro da sala de aula, para compreender as qualidades e as limitações do aplicativo, como o aplicativo pode ser empregado por professores para o aprendizado dos alunos ou como professores se adaptam ou não ao Linguiste-se. Essas questões ficam em aberto, para pesquisas futuras.

Outra limitação do aplicativo tem a ver com o número reduzido de personagens brasileiros apresentados. Seria importante continuar desenvolvendo o sistema de modo a garantir que um maior número de variedades fosse contemplado, não só na dimensão geográfica da variação. $\mathrm{Na}$ verdade, seria importante controlar características socioeconômicas, de gênero, de idade, etc. dos personagens a serem selecionados.

Por fim, com relação ao futuro do aplicativo, vale dizer que se almeja disponibilizá-lo na loja do Google: Play Store, para que usuários do sistema operacional Android possam instalá-lo em seus dispositivos; pretende-se, também, inserir uma maior quantidade de vídeos e de personagens brasileiros de modo a garantir que haja representantes da fala de todos os estados brasileiros, gerando, assim, um aplicativo com maior representatividade. 
Referências

ANTUNES, Thayane Santos. A tecnologia em prol da divulgação científica: criação de um site como meio de promoção da circulação de conhecimentos sociolinguísticos e do combate ao preconceito linguístico. 2015. 152 f. Dissertação (Mestrado em Linguística) - Instituto de Letras, Universidade do Estado do Rio de Janeiro, Rio de Janeiro, 2015.

BAGNO, Marcos. Dicionário crítico de sociolinguística. 1. ed. São Paulo: Parábola Editorial, 2017. 576 p.

BAGNO, Marcos. Preconceito linguístico: o que é, como se faz. $48^{\mathrm{a}}$ e $49^{\circ}$ ed. São Paulo: Edições Loyola, 2007.

BRASIL. MINISTÉRIO DA EDUCAÇÃO. Base Curricular Nacional Comum. Brasília: MEC/SEB, 2019 .

BRASIL. MINISTÉRIO DA EDUCAÇÃO. Parâmetros Curriculares Nacionais. terceiro e quarto ciclos do ensino fundamental. Brasília: MEC/SEB, 1998.

BREITBACH, Áurea Corrêa de Miranda. Notas sobre a importância metodológica dos conceitos. Porto Alegre, p. 121-125, 1998. Disponível em: <https://revistas.fee.tche.br/index.php/ensaios/article/viewFile/1193/1542>. Acesso em: 15/10/2019.

FARACO, Carlos Alberto. Linguagem escrita e alfabetização. 1. ed. São Paulo: Contexto, 2012. $192 \mathrm{p}$.

FREEMAN, Elisabeth. Use a Cabeça! (Head First) HTML com CSS \& XHTML. 3. ed. Rio de Janeiro: Editora Alta Books, 2008. 760 p.

GONZÁLEZ, César Augusto. Norma e variação em livros didáticos do EM. In: ZILLES, Ana Maria Stahl; FARACO, Carlos Alberto. (orgs.) Pedagogia da variação linguística: língua, diversidade e ensino. São Paulo: Parábola, 2015.

MACHADO, Flávia Cristina; LIMA, Maria de Fátima Webber Prado. O Uso da Tecnologia Educacional: Um Fazer Pedagógico no Cotidiano Escolar. Scientia cum Industria, v. 5, n. 2, p. 
44-50, 2017.2 Disponível em: $<$ http://ucs.br/etc/revistas/index.php/scientiacumindustria/article/view/528o/pdf >. Acesso em: 15/10/2019.

MILROY, James. Ideologias linguísticas e as consequências das padronizações. In: LAGARES, Xóan; BAGNO, Marcos. (orgs.) Politicas da norma e conflitos linguísticos. São Paulo: Parábola, 2012. p. 49-89.

SILVA, Maurício Samy. Ajax com jǫuery: Requisições Ajax com a simplicidade de jQ̨uery. $1^{\mathrm{a}}$ ed. São Paulo: Novatec Editora, 2009.

Data de submissão: 22/02/2020. Data de aprovação: 04/05/2020. 
APÊNDICE A - Avaliação preliminar e informal do aplicativo

1. Você se classifica como:

() Professor(a) de Língua Portuguesa

() Pedagogo(a)

2. Para você, qual a relevância do aplicativo Linguiste-se para o ensino da variação linguística?

() Muito ruim

() Ruim

( ) Razoável

() Bom

() Muito bom

3. Como você classifica a importância dos seguintes aspectos do aplicativo para o ensino?

3.1. Conteúdo do mapa linguístico

() Muito ruim

( ) Ruim

( ) Razoável

( ) Bom

() Muito bom

3.2 Definição de conceitos

() Muito ruim

() Ruim

( ) Razoável

() Bom

() Muito bom

3.3 Jogo de histórias

() Muito ruim

() Ruim

( ) Razoável

( ) Bom

( ) Muito bom 
4. Baseado na sua experiência com o aplicativo, você teria interesse em utilizá-lo?

() $\mathrm{Sim}$

( ) Não

( ) Talvez

5. Deixe aqui suas opiniões em relação ao aplicativo e sugestões para melhorias. 